\title{
Configural conditioning in the CER: A possible artifact
}

\author{
LEON J. KAMIN and FABIO IDROBO \\ Princeton University, Princeton, New Jersey 08540
}

\begin{abstract}
Gray and Lethbridge (1976) have reported a demonstration of configural conditioning in the CER in rats. With repeated reinforcement of a compound CS, suppression to the elements diminished considerably, while suppression to the compound remained substantially intact. The basic form of the Gray and Lethbridge findings has been replicated in the present study. We observed, however, that suppression to the compound itself diminished with repeated reinforcement of the compound. Further, we also tested the compound after deliberate extinction of the elements. This test of the excitatory effect of the "configural cue" indicated that it also had diminished with repeated reinforcement of the compound. The observed greater suppression to the compound than to the elements can be parsimoniously interpreted as a simple summation effect, and the attenuation of suppression with repeated reinforcement is common in CER studies. Thus, the data require no appeal to configural conditioning.
\end{abstract}

There is clear evidence that animals can learn to respond to the "configural" character of a compound CS. Pavlov (1927, p. 144) reported that differential reinforcement made it "easy" to train a dog to respond to a compound, while not responding to either element presented independently. The obverse of such a discrimination-responding to each element singly, but not to the compound-was said to occur "with equal success." Positive and/or negative patterning have also been demonstrated in American studies of dogs, rats, and rabbits. These studies, however, required many hundreds of trials to demonstrate the acquisition of patterning discriminations (Rescorla, 1972; Saavedra, 1975; Whitlow \& Wagner, 1972; Woodbury, 1943).

Patterning phenomena present obvious difficulties for theories of conditioning, such as that of Rescorla and Wagner (1972), which regard the associative strength of a compound as the sum of the strengths of its component elements. To accommodate patterning data, Wagner and Rescorla (1972) introduced into their model the concept of a configural cue. For any two stimuli presented simultaneously, a unique configural cue is generated by their joint occurrence. The configural cue has the same formal status as any other cue. Thus, a compound of two stimuli, A and $\mathrm{B}$, is regarded as containing three additive components-A, B, and $A B$. When the compound is reinforced (or nonreinforced), changes in associative strength are apportioned among the three component

This research was supported by Grant MH 16599 from the National Institute of Mental Health, United States Public Health Service. Requests for reprints should be sent to Leon J. Kamin, Department of Psychology, Princeton University, Princeton, New Jersey 08540. cues in accordance with their relative saliences. The salience of the configural cue, AB, in keeping with the belief that patterning discriminations are acquired very slowly, is said to be very weak. The configural cue thus acquires associative strength very slowly, and it gains detectable control over behavior only in situations-such as patterning studies-when it is the uniquely consistent predictor of reinforcement or nonreinforcement.

The Russian concept of "configural conditioning," as described by Razran $(1965,1971)$, is very different. This view asserts that when animals are presented with a reinforced compound they initially condition to the two elements. The compound CS, however, is "configured" as a consequence of repeated presentations. The animal then responds to the configure itself; and in some unspecified way the earlier conditioning to the separate elements disappears. This "tradeoff" from elements to configure is said to occur in simple conditioning to a compound CS, without training of a patterning discrimination. To support this view, it is asserted that Russian studies demonstrate that animals respond strongly to the component elements when tested after a few reinforced compound trials. The same animals no longer respond to the elements when tested after many more compound trials, although responding to the compound has been maintained. The problem with such demonstrations is that in a within-subject design early nonreinforced tests of the elements may transform the experiment into a positive patterning study.

The Razran configural conditioning effect, however, has recently been reported by Gray and Lethbridge (1976) in a between-subjects design. They employed rats in a CER procedure, with different groups receiving from 4 to 60 reinforced light-noise 
compounds before being tested to the individual elements. They observed almost complete suppression to each element after 8 and 12 reinforced compounds, but much less suppression to the elements after 24,40 , and 60 reinforced compounds. Though suppression to the compound gradually diminished after 12 reinforcements, it remained much greater than suppression to either element alone.

There are major problems in interpreting the Gray and Lethbridge data as a demonstration of configural conditioning. The observed greater response to the compound than to either element may reflect a simple summation effect. That is, the combined presentation of two moderately excitatory stimuli can produce a strongly excitatory effect (Reberg, 1972). Further, the observed loss of suppression to the elements with repeated compound reinforcements is consistent with the common observation (Annau \& Kamin, 1961; Millenson \& Hendry, 1967) of a postasymptotic performance decrement in CER studies. Gray and Lethbridge, in fact, also observed a loss of suppression to the compound with repeated reinforcements.

The core of the configural conditioning notion is that responding to the "configural cue" should increase during the same trials when responding to the elements is decreasing. The Gray and Lethbridge study made no attempt to measure responding to the configural cue directly. The present experiment attempted to repeat and extend the Gray and Lethbridge results. With a between-subjects design, responding to elements was tested after 6 and after 16 reinforced compounds. We included, however, an independent test of the strength of the configural cue itself. The basic question was whether, with repeated reinforcement of the compound, the strength of the configural cue increases, while that of the elements decreases.

\section{METHOD}

\section{Subjects and Apparatus}

The subjects were 16 experimentally naive Holtzman male albino rats, obtained commercially at about $300 \mathrm{~g}$ weight. They were reduced to $75 \%$ of their ad-lib weights and were maintained throughout the study on a $24-\mathrm{h}$ feeding rhythm. The apparatus consisted of eight standard operant conditioning units housed in lightproof and sound-attenuating boxes. Programming and recording equipment were located in an adjacent room.

\section{Procedure}

Following initial magazine training, all animals received five daily 2-h barpress sessions under a 2.5 -min VI schedule. The reinforcements were $45-\mathrm{mg}$ food pellets. The last two preliminary training sessions each contained two pretest presentations of the light and noise stimuli. These stimuli, later to serve as CSs, were each $3 \mathrm{~min}$ in duration. The light $\mathrm{CS}$ consisted of the illumination of an overhead 7.5-W bulb in an otherwise completely dark chamber. The noise stimulus was an $80-\mathrm{dB}$ re $20 \mu \mathrm{N} / \mathrm{m}^{2}$ white noise presented against an ambient noise level of about $65 \mathrm{~dB}$.

For CER conditioning, the animals were randomly divided into two groups of eight rats each. The only difference between the two groups was the number of reinforced compound CER trials. For all animals, daily 2-h barpress sessions continued, but two irregularly spaced CS-US pairings were now presented within each session. The CS consisted of the simultaneous presentation of light and noise for $3 \mathrm{~min}$. The US was a scrambled .5-sec, $1-\mathrm{mA}$ shock delivered to the grid floor on which the rat stood, concurrently with termination of the CS. There were $3 \mathrm{CER}$ conditioning days ( 6 reinforced compounds) for Group C- 6 . There were 8 conditioning days ( 16 reinforced compounds) for Group C-16. The CER conditioning of Group C- 6 was begun on the 6th CER day of Group C-16, so that test sessions could be given to both groups on the same experimental day.

The first test session was conducted on the day following completion of CER conditioning. For each animal, there were two nonreinforced presentations of light and two of noise, in an alternating sequence. The order of presentation (light or noise first) was counterbalanced within groups.

The following day, the animals in each group received massed extinction to the light and noise stimuli. There were seven presentations of light and seven of noise, in alternating order, spaced approximately $8 \mathrm{~min}$ apart. Finally, the last test trial consisted of a simultaneous presentation of the light and noise in compound. The purpose of this final test trial was to assess the associative strength of the configural cue. The prior extinction of the elements, if successfully completed, should leave the configural cue as the only excitatory component of the compound.

\section{Measures}

Throughout conditioning and testing, suppression ratios were calculated for each subject on each trial. The ratio is $B /(A+B)$, where $B$ represents number of barpresses during the $C S$, and $A$ the number in the immediately preceding 3 -min period. Thus a ratio of .50 indicates no effect of the CS on barpressing, while .00 indicates complete suppression.

\section{RESULTS}

The acquisition of the CER is portrayed for each group in Figure 1. Four reinforcements of the compound were sufficient to establish almost complete suppression. There were not, of course, significant differences between groups during the first six acquisition trials. The mean ratio of Group C-16 on Trial 16 did not differ significantly from that of Group C-6 on Trial 6. This between groups comparison, how-

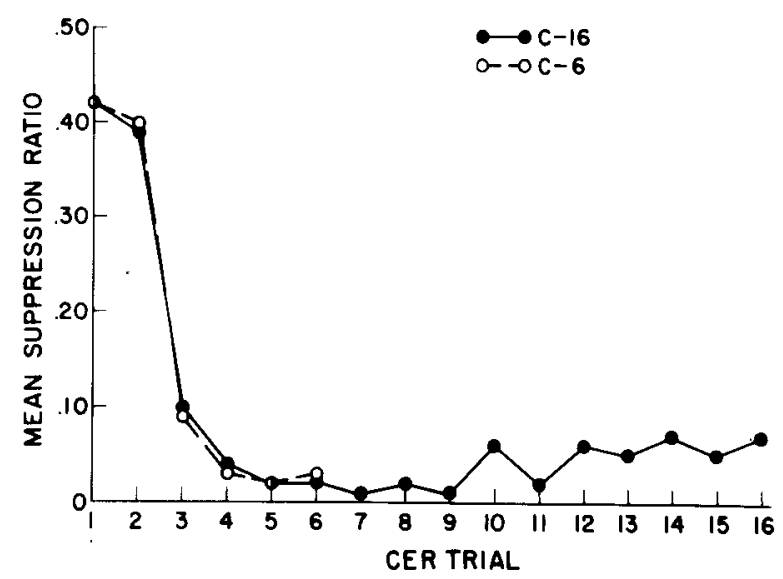

Figure 1. Mean suppression ratios to the compound CS for each trial of CER acquisition. 


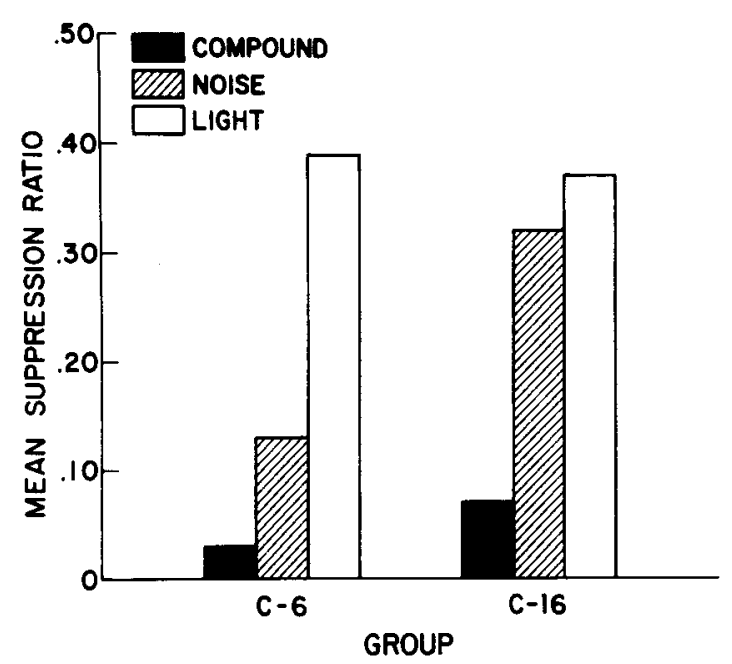

Figure 2. Mean suppression ratios for each group for the last reinforced compound trial, and for the first test trial to noise and to light.

ever, is not sensitive enough to detect a slight attenuation of suppression to the compound. Within Group C-16, the mean ratio was .02 for Trials 5-8, .04 for Trials 9-12, and .06 for Trials 13-16. This was a significant effect $[F(2,14)=4.99, p<.05]$.

The results of the first test trial to each element are presented in Figure 2, together with the results of the last reinforced compound trial in each group. There is obviously, in each group, much less suppression to the elements than to the compound. The light test ratio was higher than that of the last reinforced compound in every subject, and the noise ratio was higher in every subject but one. The data for the test trials to the elements were submitted to a mixed analysis of variance. The overall difference between groups was significant $[F(1,14)=6.99, p<.05]$, with Group C-6 showing more suppression to the elements. The effect of stimulus was also significant $[F(1,14)=7.01, p<.05]$, with noise eliciting more suppression than light. The Group by Stimulus interaction fell short of significance $[F(1,14)=3.53$, $.10>\mathrm{p}>.05$ ]. With individual $\mathrm{t}$ tests, there was no significant difference between groups in suppression to the light, but Group C-6 suppressed more to noise than did Group C-16 [t(14) $=2.87, \mathrm{p}<.02]$. Furthermore, the difference between stimuli was not significant in Group C-16, but was so in Group C-6 $[\mathrm{t}(7)=4.57, \mathrm{p}<.01]$.

The second pair of test trials to the elements produced no new information other than a general weakening of suppression as a consequence of nonreinforcement of the preceding test trials. The massed extinction training produced a rapid loss of suppression to each element. The final extinction trials produced mean ratios of .47 to light and .50 to noise, with no significant difference between stimuli or between groups.
The results of the final compound test trial (the test of the configural cue) were clear. Though conditioning to the elements had been extinguished, mean ratios to the compound were .17 in Group C-6 and .39 in Group C-16. The two groups differed significantly $[\mathrm{t}(14)=3.12, \mathrm{p}<.01]$. That is the group which had received more compound reinforcements displayed less suppression to the configural cue.

\section{DISCUSSION}

The strongest demonstration of configural conditioning would require suppression to the configural cue to increase-or at least not to decrease-during the same reinforced compound trials when suppression to the elements is diminishing. This did not occur. The test of the configural cue included in the present study indicated that it, like the elements, lost strength with repeated reinforcement of the compound. There is thus no evidence, either in the present study or in that of Gray and Lethbridge, that responding to a configure increases while responding to the elements decreases.

We observed, as did Gray and Lethbridge, considerable weakening of suppression to the elements during a series of reinforced compound trials. Further, as in their data, there was a slight, but significant, loss of suppression to the compound itself during the reinforced compound trials. Thus, in our Group C-16 we also obtained an outcome said to characterize configural conditioning-strong suppression to the compound and little suppression to either element. This outcome, however, can be regarded as the product of two well-established phenomena. The strong suppression to the compound can be reasonably interpreted as the summed effect of two moderately excitatory elements (Reberg, 1972). The loss of suppression with continued reinforcement has often been reported (Millenson \& Hendry, 1967). The loss of suppression, it should be noted, was not unique to the elements, but was also observed in the configural cue test, as well as in responding to the reinforced compound. The results of the present study, like the data of Gray and Lethbridge, thus require no appeal to the concept of configural conditioning.

To assess conditioning to the configural cue per se, the present study included a test to the compound after conditioning to the elements had been deliberately extinguished. That test produced significant suppression, but much more in Group C-6 than in Group C-16. This might be taken to imply that substantial conditioning had occurred to the configural cue within six reinforced trials, as it had to the elements-but that suppression to all cues attenuated with continued reinforcement of the compound. Possibly, however, the suppression observed on the configural-cue test trial represents a summation of 
undetected excitation still occurring to the elements after massed extinction. The present data cannot distinguish between these two alternatives.

The fact that the present study did demonstrate a significant loss of suppression to the noise element, but not to the light, seems obviously a consequence of the greater salience of the noise. There was much more suppression to noise than to light in Group C-6, and the element which acquires more strength of course has more to lose. The acquisition of the CER, as well as the loss of suppression by the elements, was more rapid in the present study than in that of Gray and Lethbridge. Thus, it seems likely that if we had tested the elements after four compound trials we would have observed more suppression to light (and to noise) than was displayed by Group C-6. We know from much past experience with the light CS that, when reinforced independently, it elicits almost complete suppression after four trials.

Finally, there remains the question of what is responsible for the attenuation of suppression with continued reinforcement. Part of the decrement is due, as indicated by Gray and Lethbridge, to the development of inhibition of delay. Within the present study, mean suppression to the compound on Day 8 of CER conditioning was, during consecutive 1 -min segments of the CS, .12, .02, and .02. This significant, but modest, inhibition of delay effect does not seem sufficient to account for the large and rapid decrements often observed in CER studies. Possibly, as Annau and Kamin (1961) suggested, adaptation to the shock US is involved. Whatever the cause of the decrement, it is important to distinguish such effects from a loss of "associative strength." Thus, when testing theoretical predictions about the associative strengths of cues, it is essential to control for, or to discount, nonassociative response decrements which occur with repeated reinforcement.

\section{REFERENCES}

Annau, Z.. \& Kamin, L. J. The conditioned emotional response as a function of intensity of the US. Journal of Comparative and Physiolngical Psychology, 1961, 54, 428-432.

Gray, T., \& Lethbridge, D. A. Configural conditioning in the CER: Loss of element strength after repeated reinforced compound CS trials. Learning and Motivation, 1976, 7, 532-539.

Millenson, J. R.. \& Hendry, D. P. Quantification of response suppression in conditioned anxiety training. Canadian Journal of Psychology, 1967, 21, 242-252.

Pavlov, I. P. Conditioned reflexes. London: Oxford University Press. 1927.

Razran, G. Empirical codification and specific theoretical implications of compound-stimulus conditioning: Perception. In W. F. Prokasy (Ed.), Classical conditioning. New York: Appleton-Century-Crofts, $1 \% 5$.

Razran, G. Mind in evolution. Boston: Houghton Mifflin, 1971.

REBERG, D. Compound tests for excitation in early acquisition and after prolonged extinction of conditioned suppression. Learning and Motivation, 1972, 3, 246-258.

Rescorla, R. A. "Configural" conditioning in discrete-trial bar pressing. Journal of Comparative and Physiological Psychology. 1972, 79, 307-317.

Rescorla, R. A., \& W Agner, A. R. A theory of Pavlovian conditioning: Variations in the effectiveness of reinforcement and nonreinforcement. In A. H. Black \& W. F. Prokasy (Eds.), Classical conditioning II. New York: Appleton-CenturyCrofts, 1972.

SaAvedra, M. A. Pavlovian compound conditioning in the rabbit. Learning and Motivation, 1975, 6. 314-326.

W AGner, A. R., \& Rescorla, R. A. Inhibition in Pavlovian conditioning: Application of a theory. In R. A. Boakes \& M. S. Halliday (Eds.), Inhibition and learning. New York: Academic Press, 1972

Whitlow, J. W., JR., \& W AGNER, A. R. Negative patterning in classical conditioning: Summation of response tendencies to isolable and configural components. Psychonomic Science, 1972, 27, 299-301.

Woodbury, C. B. The learning of stimulus patterns by dogs. Journal of Comparative Psychology, 1943, 35, 29-40.

(Received for publication October 28, 1977; revision accepted January 23, 1978.) 